\title{
Determination of lactate value
}

Determinação do valor de lactato

\author{
Viroj Wiwanitkit' \\ Wiwanitkit House, Bangkhae, Bangkok, Thailand
}

\author{
'MD, PhD. Professor, Wiwanitkit House, Bangkhae, \\ Bangkok, Thailand. \\ "MD. Attending physician in the Intensive Care \\ Unit, Discipline of Anesthesiology, Pain and \\ Intensive Care, Universidade Federal de São \\ Paulo - Escola Paulista de Medicina (Unifesp- \\ EPM), São Paulo, Brazil. \\ "'MD, MSc. Coordinator of the Intensive Care \\ Unit, Discipline of Anesthesiology, Pain and \\ Intensive Care, Universidade Federal de São \\ Paulo - Escola Paulista de Medicina (Unifesp- \\ EPM), São Paulo, Brazil. \\ IvMD. Coordinator of the Intensive Care Unit, \\ Discipline of Anesthesiology, Pain and Intensive \\ Care, Universidade Federal de São Paulo - \\ Escola Paulista de Medicina (Unifesp-EPM), São \\ Paulo, Brazil. \\ ${ }^{\mathrm{V}} \mathrm{MD}, \mathrm{PhD}$. Adjunct Professor, Discipline of \\ Anesthesiology, Pain and Intensive Care, \\ Universidade Federal de São Paulo - Escola \\ Paulista de Medicina (Unifesp-EPM), São Paulo, \\ Brazil.
}

\section{Dear Editor,}

I read a recently published paper on determination of lactate values with great interest. ${ }^{1}$ It was concluded that "Lcen, and not Lper, can replace Lart with good correlation and clinical agreement. Lper tends to overestimate Lart, thus leading to unnecessary therapeutic interventions". There are some concerns regarding this work. First, it has to be clarified that the lactate levels determined at each site are not the same. The values from arterial, venous and capillary blood cannot be interchanged with each another. Second, the quality control for the analytical technique should be mentioned. In general practice, a point-of-care testing tool might be used for capillary blood samples, while a standard clinical chemistry analyzer might be used for arterial and venous blood samples. This may simply result in differences.

\section{REFERENCES}

1. Nascente AP, Assunção M, Guedes CJ, et al. Comparison of lactate values obtained from different sites and their clinical significance in patients with severe sepsis. Sao Paulo Med J. 2011;129(1):11-6.

Sources of funding: None

Conflict of interest: None

Date of first submission: May 23, 2011

Last received: May 23, 2011

Accepted: August 23, 2011

Address for correspondence:

Professor Viroj Wiwanitkit

Wiwanitkit House, Bangkhae, Bangkok, Thailand 10160

Tel. (+66) 24132436

E-mail:wviroj@yahoo.com 